\title{
Original Article \\ Predictors of quality of life in breast cancer patients under chemotherapy
}

\author{
Safaee A ${ }^{1}$, Moghimi-Dehkordi B ${ }^{2}$, Zeighami B⿳亠丷厂 ${ }^{3}$ Tabatabaee HR $^{4}$, Pourhoseingholi MA \\ 1,2,5 Department of HSR, Research Center of Gastroenterology and Liver Diseases, Shahid Beheshti \\ University (MC), Tehran, ${ }^{3,4}$ Department of Epidemiology. Faculty of Health School. Shiraz University of \\ Medical Sciences, Shiraz, Iran.
}

Correspondence to: Dr. Azadeh Safaee, E-mail: azadesafaee@yahoo.com

\begin{abstract}
BACKGROUND: Today, the quality of life studies has an important role in health care especially in chronic diseases. Breast cancer has third order among women's malignancies. Now, survival rate for this cancer is long. However breast cancer has several complications that affected the patient's life. AIMS: The aim of this study was to assess the quality of life in Breast cancer patients under chemotherapy. SETTING AND DESIGN: A cross-sectional study conducted on 119 breast cancer patients that were admitted and treated in chemotherapy ward of Namazi hospital in Shiraz city, south of Iran, between Jan and Feb 2006. MATERIALS AND METHODS: The QLQ-C30 questionnaire was used to assess quality of life in these patients. STATISTICAL ANALYSIS: We used univariate methods. A multiple regression analysis was performed to identify predictors of quality of life. RESULTS: Mean age of patients was $48.27 \pm 11.42$ with quality of life total score $64.92 \pm 24.28$. All symptoms scales had reverse association with quality of life except appetite loss $(P>0.05)$ and diarrhea $(P=0.752)$. The results of the regression analyses showed that only grade of tumor, occupational status, menopausal status, financial difficulties and dyspnea were statistically significant in predicting patients' quality of life. CONCLUSION: In conclusion, this study demonstrates the strength of the relationship between clinical and sociodemographical factors and breast cancer patients' quality of life. Psychological and financial support for women experiencing breast cancer diagnosis may improve quality of life.
\end{abstract}

Key words: Breast cancer, functioning scales, symptoms scales, quality of life, QLQ-C30

\section{Introduction}

Quality of life (QOL) is a very frequently applied concept nowadays. ${ }^{[1]}$ It is a subjective concept and its definitions and the sub concepts involved have varied. QOL has been defined as the subjective evaluation of life as a whole or the patient's appraisal and satisfaction with their current level of functioning compared with what they perceive to be possible or ideal. ${ }^{[2]}$ In a simple way, QOL is individual imaginations or thoughts from life style according to his/her objectives, expectations, standards and preferences. QOL is a multidimensional construct encompassing perceptions of both positive and negative aspects of dimensions such as physical, emotional, social and cognitive functions, as well as the negative aspects of somatic discomfort and other symptoms produced by a disease or its treatment. ${ }^{[2]}$

Today, quality of life survey is an important issue in health care, especially oncological researches .C ancer affects on different aspects of QOL and at present time, cancer disease is a major problem in I ran and whole of the world. Among these cancer diseases, breast cancer is the most common cancer in women. ${ }^{[3]}$ D uring last decades, survival rates for breast cancer have increased as a result of earlier detection and increased use of adjuvant therapy. ${ }^{[4]}$ Women may also receive radiation therapy and/ or chemotherapy plus systemic hormonal therapy for breast cancer treatment depending on stage and estrogen receptor status at diagnosis. L ong-term consequences of therapy include painful and often debilitating lymph edema due to surgery or radiation therapy consequently, these patients are engaged with cancer and its outcomes and effects, for a long time. Therefore, it is critical for health care professionals to become familiar with the impact of a breast cancer diagnosis and its treatment on patient's Q OL. ${ }^{[3]}$ The aim of this study was to assess breast cancer patients' QOL and recognize the factors that affect QOL. 


\section{Materials and Methods}

We conducted a cross-sectional study on 119 random samples of breast cancer patients that were admitted and treated in the chemotherapy ward of $\mathrm{N}$ amazi hospital in Shiraz city, south of I ran between December 2005 to February 2006. This center is a referral center in south of province. Any patients with a new diagnosis of breast cancer, according to pathology report, under chemotherapy were eligible to enter the study.

The exclusion criteria were: cancer diagnosis less than two months; recurrent of breast cancer cognitive impairment; other previous or concurrent malignancies.

We used Q L Q-C30 questionnaire to assessment Q O L in these patients. This questionnaire is a valid and reliable questionnaire for evaluation of quality of life in Iran. ${ }^{[5]}$ The Q LQ-C30 questionnaire is a self-report multidimensional general cancer-specific questionnaire, which was designed to assess Q O L in cancer patients. The QLQ-C30 proved useful in many clinical trials, because it assesses the main factors influencing HRQOL of patients with cancer. . $^{[5]}$ The Q LQ $-C 30$ is multidimensional, made up of 30 items (five functional domains: physical, role, emotional, cognitive, and social, one global QOL domain, three symptom domains: fatigue, nausea-vomiting, pain, and six single items). The scores are transformed into 0-100 point scales. In the case of the five functional scales and the global QOL scale, the high score means: 'high level of functioning or global Q OL'. On the other hand, in the case of symptom scales and single items, the higher score implies the higher level of symptoms or problems. ${ }^{[8-10]}$

Sociodemographic data included age, education, occupation and marital status, and Clinical data including grade of tumor, metastasis, type of treatment, type of first treatment, co-morbidity, type of treatment, type of first treatment, duration of disease and status of menopause gathered by additional questionnaire.

The study protocol has been approved in ethical committee of Shiraz U niversity of medical science. Before the interview survey, the interviewer explained the purpose of these questions to all eligible individuals and requested their participation.

We used univariate methods such as K ruskalwallis, $M$ ann-W hitney $U$ and Spearman correlation tests. A multiple regression analysis was performed to identify predictors of $Q O L$. For this procedure, the global QOL score of the EORTC QLQ-C 30 was treated as the dependent variable. Sociodemographic, medical characteristics and symptom of disease were entered as

108 explanatory factors in the model.[11-13] All calculation performed using SPSS.V.13.

\section{Results}

Total of 119 patients with breast cancer were interviewed. The demographic and clinical characteristics of the baseline sample are shown in [Table 1]. The mean age was $48.27(S D=11.42)$ years, and most of the patients were married $(73.9 \%)$. The level of education in our study sample was relatively low concerning employment status, most of women were housekeeper or retired and only $17.6 \%$ were employed before the cancer was diagnosed.

The mean score for the global health status for breast cancer patients was $64.92 \pm 11.42$. The best functional outcomes were found for the cognitive and social functioning subscales and emotional functioning scored the lowest. Breast cancer patients were suffered from insomnia, fatigue and pain. Other symptoms such as diarrhea, constipation, dyspnea, nausea and vomiting and appetite loss were reported less severity [Table 2].

In univariate analysis, among demographic factors (such as age, education, marital status and occupation) only occupational status was associated with Global Q uality of life, and employed women had better Q O L

\begin{tabular}{|c|c|c|c|c|}
\hline Variable & & Number & $\%$ & $P$ value \\
\hline Age & $\begin{array}{l}<35 \\
35-50 \\
>50\end{array}$ & $\begin{array}{l}14 \\
55 \\
50\end{array}$ & $\begin{array}{r}11.8 \\
46.2 \\
42.0\end{array}$ & 0.185 \\
\hline Education & $\begin{array}{l}\text { Illiterate and primary } \\
\text { Diploma and lower } \\
\text { University }\end{array}$ & $\begin{array}{l}68 \\
41 \\
10\end{array}$ & $\begin{array}{c}57.1 \\
34.5 \\
8.4\end{array}$ & 0.824 \\
\hline Occupation & $\begin{array}{l}\text { Employee } \\
\text { Housekeeper and } \\
\text { retired }\end{array}$ & $\begin{array}{l}21 \\
98\end{array}$ & $\begin{array}{r}17.6 \\
82.4\end{array}$ & 0.036 \\
\hline Marital status & $\begin{array}{l}\text { Married } \\
\text { Other }\end{array}$ & $\begin{array}{l}88 \\
31\end{array}$ & $\begin{array}{l}73.9 \\
26.1\end{array}$ & 0.655 \\
\hline $\begin{array}{l}\text { Duration of } \\
\text { disease }\end{array}$ & $\begin{array}{l}<4 \text { month } \\
4-12 \text { month } \\
>12 \text { month }\end{array}$ & $\begin{array}{l}47 \\
41 \\
31\end{array}$ & $\begin{array}{l}39.5 \\
34.4 \\
26.1\end{array}$ & 0.017 \\
\hline Metastasis & $\begin{array}{l}\text { Yes } \\
\text { No }\end{array}$ & $\begin{array}{l}26 \\
93\end{array}$ & $\begin{array}{l}21.8 \\
78.2\end{array}$ & 0.824 \\
\hline Grade of tumor & $\begin{array}{l}\text { Well differentiated } \\
\text { Moderately } \\
\text { differentiated } \\
\text { Poorly differentiated }\end{array}$ & $\begin{array}{l}40 \\
50 \\
29\end{array}$ & $\begin{array}{l}33.6 \\
42.0\end{array}$ & $<0.0001$ \\
\hline
\end{tabular}

Indian Journal of Cancer | July-September 2008 | Volume 45 | Issue 3 
Table 2: Mean and standard deviation of EORTC QLQ-C30 subscale scores and their correlation with global health status in breast cancer patients

\begin{tabular}{lcccc}
\hline Scales & $\begin{array}{c}\text { Mean } \\
\text { (\%) }\end{array}$ & $\begin{array}{c}\text { Standard } \\
\text { deviation }\end{array}$ & $\begin{array}{c}\text { Correlation } \\
\text { coefficient }\end{array}$ & $\boldsymbol{P}$ value \\
\hline Functioning & \multicolumn{5}{l}{} \\
\hline Physical & 57.31 & 23.76 & 0.230 & 0.012 \\
\hline Role & 65.27 & 34.89 & 0.107 & 0.240 \\
\hline Emotional & 56.26 & 30.84 & 0.273 & 0.003 \\
\hline Cognitive & 72.27 & 27.47 & 0.337 & $<0.0001$ \\
\hline Social & 69.61 & 32.95 & 0.133 & 0.148 \\
\hline Symptoms & & & & \\
\hline Fatigue & 41.74 & 26.91 & -0.219 & 0.016 \\
\hline Nausea and vomiting & 16.39 & 28.37 & -0.244 & 0.007 \\
\hline Pain & 33.19 & 28.25 & -0.287 & 0.002 \\
\hline Dyspnea & 16.25 & 27.05 & -0.192 & 0.036 \\
\hline Insomnia & 43.7 & 40.65 & -0.216 & 0.018 \\
\hline Appetite loss & 22.69 & 36.29 & -0.059 & 0.524 \\
\hline Constipation & 14.85 & 29.34 & -0.258 & 0.005 \\
\hline Diarrhea & 3.92 & 16.34 & 0.092 & 0.319 \\
\hline Global health status 64.92 & 11.42 & 1.00 & - \\
\hline
\end{tabular}

$(P=0.036)$. D uration of disease was significantly related to QOL score of patients. In other words, those with duration of disease less than four months reported significantly lesser global Q OL score $(P=0.017)$. Results of univariate analysis show significant differences in global QOL scores, where patients with poor grade have the worst $(P<0.0001)$. No significant association observed between QOL and other clinical factors (such as metastasis of tumor, type of treatment, type of first treatment, comorbidity, duration of disease and status of menopause). All symptoms scales had reverse association with Q OL except appetite loss $(P=0.285)$ and diarrhea $(P=0.752)$. Also, $Q O L$ in breast cancer patients was affected by financial difficulties $(P=0.019)$.

The results of the regression analyses showed that only grade of tumor, occupational status, menopausal status, financial difficulties and dyspnea were statistically significant in predicting patients' QOL [Table 3]. Duration of disease, and other symptom scales were not significant.

\section{Discussion}

This study demonstrates the consistency and strength of the relationship between grade of tumor, occupation, dyspnea, menopause status and financial difficulties and breast cancer patients' quality of life. The strongest

\begin{tabular}{|c|c|c|c|c|c|c|}
\hline \multirow[b]{2}{*}{ Variable } & \multicolumn{3}{|c|}{ Full model } & \multicolumn{3}{|c|}{ Final model } \\
\hline & $\beta$ & SE $(\beta)$ & $P$ value & $\beta$ & SE $(\beta)$ & $P$ value \\
\hline Physical functioning & -0.121 & 0.136 & 0.377 & - & - & - \\
\hline Role functioning & 0.026 & 0.095 & 0.786 & - & - & - \\
\hline Emotion functioning & -0.021 & -0.026 & 0.827 & - & - & - \\
\hline Cognitive functioning & 0.221 & 0.105 & 0.038 & - & - & - \\
\hline Social functioning & -0.222 & 0.123 & 0.073 & - & - & - \\
\hline Fatigue & -0.065 & 0.112 & 0.562 & - & - & - \\
\hline Nausea and vomiting & -0.110 & 0.080 & 0.175 & - & - & - \\
\hline Pain & -0.162 & 0.109 & -0.142 & - & - & - \\
\hline Dyspnea & -0.161 & 0.082 & -0.177 & -0.091 & 0.046 & 0.01 \\
\hline Insomnia & -0.079 & 0.055 & 0.156 & - & - & - \\
\hline Constipation & 0.011 & 0.080 & 0.895 & - & - & - \\
\hline Financial difficulties & -0.109 & 0.053 & 0.044 & -0.059 & 0.029 & 0.03 \\
\hline Grade of tumor & -16.05 & 3.1 & $<0.0001$ & -15.74 & 2.75 & $<0.0001$ \\
\hline Duration of disease & 6.711 & 5.568 & 0.231 & - & - & - \\
\hline Menopause & 6.498 & 4.294 & 0.134 & 6.66 & 2.43 & 0.01 \\
\hline Occupation & 7.643 & 5.500 & 0.168 & 8.86 & 3.19 & 0.01 \\
\hline First treatment & -7.199 & 5.300 & 0.178 & - & - & - \\
\hline
\end{tabular}


influence on QOL in our study was grade of tumor.

These assessments showed that the emotional functioning score and the physical scores were lower compared to the other QOL subscale scores. This might be due to the fact that patients were informed about their cancer diagnosis. Facing a life-threatening illness and the uncertainty of treatment outcomes is psychologically distressing. During the active phase of treatment physical functioning has an enormous impact on QOL. Patients may experience acute side effect of the treatment in addition to cancer-related symptoms which can be emotionally distressing and debilitating. Previous studies have demonstrated the relationship between physical factors and emotional distress. ${ }^{[14-16]}$ After the completion of cancer treatment, patients are usually able to return to a level of physical functioning consistent with that of their pre-cancer diagnosis. ${ }^{[16]}$

Concerning demographic factors (age, education, and marital status) the subgroups did not differ from one another. Some research, but not all, indicates that younger women may suffer poorer QOL following a breast cancer diagnosis. ${ }^{[17,18]}$ U nfortunately, age definitions vary across studies. This association wasn't seen in our study. In line with other findings, in the present study, employment status was significantly associated with QOL.[4,16]

Postmenopausal women had better QOL. This relation may be confounded by effect of age. O ur findings suggest that financial status may also play an important role in determining QOL. Developing a chronic illness or having a spouse with chronic illness like cancer would mean loss of that day's income, and extra expenditures and influence many aspects of life. ${ }^{[19,20]}$

H owever, the regression model explained only $73.6 \%$ of the variance. There may be other variables, such as toxicity or symptom distress, which have not been sufficiently considered in this study.

Interpretation of our data must consider some limitations (e.g. sample size and study design). The cross-sectional design allowed identification of several factors associated with QOL, although causal inferences could not be made. Factors related to QOL impairment were identified (e.g. grade of tumor, occupation, financial difficulties, and etc.).

The findings of this study should be the target of further research, emphasizing the need for interventional studies that minimize the negative impact of the disease symptoms on the QOL in women with breast cancer. Prospective studies are needed to evaluate the influence of other factors (education, socioeconomic status, type of surgery, quality of partner relationship) on QOL. Future research should include a comparable group of women without breast cancer, seeking to identify whether QOL and its associated factors are similar among women with and without breast cancer.

\section{Conclusion}

In conclusion, this study demonstrates the consistency and strength of the relationship between clinical and sociodemographical factors and breast cancer patients' quality of life. Psychological and financial support for women experiencing breast cancer diagnosis may improve QOL.

\section{Acknowledgments}

We would like to thank the staff of the Chemotherapy ward of $\mathrm{N}$ amazi $\mathrm{H}$ ospital for their valuable collaboration in this study and EORTC quality of life group for their permission to use of QL Q-C30 questionnaire.

\section{References}

1. Billingham LJ, Abrams KR, Jones DR. Methods for the analysis of quality of life and survival data in health technology assessment. Health Technol Asess 1999;3:1-152.

2. Lehto US, Ojanen M, Kellokumpu-Lehtinen P. Predictors of quality of life in newly diagnosed melanoma and breast cancer patients. Ann Oncol 2005; 16:805-16.

3. Engel J, Kerr J, Schlesinger-Raab A, Eckel R, Sauer H, Hölzel D. Predictors of quality of life of breast cancer patients. Acta Oncol 2003;42:710- 8.

4. Ganz PA, Kwan L, Stanton AL, Krupnick JL, Rowland JH, Meyerowitz $\mathrm{BE}$, et al. Quality of life at the end of primary treatment of breast cancer: First results from the moving beyond cancer randomized trial. J Natl Cancer Inst 2004;96:376- 87.

5. Safaee A, Dehkordi BM. Validation Study of a Quality of Life (QOL) questionnaire for use in Iran. Asian Pac J Cancer Prev 2007;8:543-6.

6. Bjordal K, de Graeff A, Fayers PM, Hammerlid E, van Pottelsberghe C, Curran D, et al. A 12 country field study of the EORTC QLQ-C30 (Version 3.0) and the head and neck cancer specific module (EORTC QLQ-H and N35) in head and neck patients: EORTC Quality of Life Group. Eur J Cancer 2000;36: 1796-807.

7. Aaronson NK, Ahmedzai S, Bergman B, Bullinger M, Cull A, Duez NJ, et al. The European Organization for Research and Treatment of Cancer QLQ-C30: A quality of life instrument for use in international clinical trials in oncology. J Natl Cancer Inst 1993;85:365-76.

8. Fayers PM, Aaronson NK, Bjordal K, Groenvold M, Curran D, Bottomley A, on behalf of the EORTC Quality of Life Group. EORTC QLQ-C30 Scoring Manual, $3^{\text {rd }}$ ed. Brussels: EORTC; 2001.

9. Toth G, Sakaguchi T, Mikami Y, Hirose H, Tsukuda M. A pilot study of the translation, cultural adaptation and validation of the EORTC head and neck cancer quality of life questionnaire module (QLQHandN35) for use in Japan. Auris Nasus Larynx 2005;32: 175-83.

10. Hopwood P, Haviland J, Mill J, Sumo G, M Bliss J; START Trial Management Group. The impact of age and clinical factors on quality of life in early breast cancer: An analysis of 2208 women recruited to the UK START Trial (Standardization of Breast Radiotherapy Trial). Breast 2007; 16:241-51.

Indian Journal of Cancer | July-September 2008 | Volume 45 | Issue 3 
11. Fayers PM, Machin D. Missing data. In: Quality of life: assessment, analysis and interpretation. Chichester: Wiley; 2000. p. 224-47.

12. Fariclough D. Design and analysis of quality of life studies in clinical trials. $1^{\text {st }}$ ed. Chapman and Hall/CRC; 2000.

13. Kleinbaum D, Kupper L. Applied regression analysis and other multivariable methods. $1^{\text {st }}$ ed. Boston: Duxburg Press; 1978. p. 188-209.

14. Hartl K, Janni W, Kastner R, Sommer H, Strobl B, Rack B, et al. Impact of medical and demographic factors on long term quality of life and body image of breast cancer patients. Ann oncol 2003; 14: 1067-71.

15. Avis NE, Crawford S, Manuel J. Quality of life among younger women with breast cancer. J Clin Oncol 2005;23:3322-30.

16. Greimel E, Thiel I, Peintinger F, Cegnar I, Pongratz E. Prospective assessment of quality of life of female cancer patients. Gynecol Oncol 2002;85: 140-7.

17. Arndt V, Merx H, Stegmaier C, Ziegler H, Brenner H. Persistence of restrictions in quality of life from the first to third year after diagnosis in women with breast cancer. J Clin Oncol 2005;23:4945-53.

18. Klee M, Thranov I, Machin D. Life after radiotherapy: The psychological and social effects experienced by women treated for advanced stages of cervical cancer. Gynecol Oncol 2000;76:5-13.

19. Casso D, Buist DS, Taplin S. Quality of life $5-10$ years breast cancer survivors diagnosed between age 40 and 49 . Health Quality Life Outcomes 2004;2:25-9.

20. Pandey M, Thomas BC, SreeRekha P, Ramdas K, Ratheesan K, Parameswaran S, et al. Quality of life determinants in women with breast cancer undergoing treatment with curative intent. World J Surg Oncol 2005;3:63-72.

Source of Support: Shiraz University of Medical Sciences, Conflict of Interest: None.

Announcement

\section{Dispatch and return notification by E-mail}

The journal now sends email notification to its members on dispatch of a print issue. The notification is sent to those members who have provided their email address to the association / journal office. The email alerts you about an outdated address and return of issue due to incomplete / incorrect address.

If you wish to receive such email notification please send your email along with the membership number and full mailing address to the editorial office by email. 